\title{
The history of endourology in Canada
}

\author{
Darren Beiko, MD, MBA, FRCSC ${ }^{1}$; R. John D’A. Honey, MA, MB BChir, FRCS, \\ FRCSC $^{2}$; Kenneth T. Pace, MD, MSc, FRCSC ${ }^{2}$; John D. Denstedt, MD, FRCSC, FACS, \\ FCAHS $^{3}$; Hassan Razvi, MD, FRCSC ${ }^{3}$; Denis H. Hosking, MD, FRCSC ${ }^{4}$; Richard W. \\ Norman, MD, FRCSC ${ }^{5}$; James W.L. Wilson, MD, FRCSC, FACS ${ }^{1}$ \\ ${ }^{1}$ Department of Urology, Queen's University, Kingston, ON, Canada; ${ }^{2}$ Division of Urology, Department of \\ Surgery, University of Toronto, Toronto,ON, Canada; ${ }^{3}$ Division of Urology, Department of Surgery, \\ Schulich School of Medicine and Dentistry, Western University, London, ON, Canada; ${ }^{4}$ Department of \\ Surgery, Section of Urology, University of Manitoba, Winnipeg, MB, Canada; ${ }^{5}$ Department of Urology, \\ Dalhousie University, Halifax, NS, Canada
}

Cite as: Can Urol Assoc J 2019 February 7; Epub ahead of print. http://dx.doi.org/10.5489/cuaj.5747

Published online February 7, 2019

$* * *$

\section{Abstract}

Introduction: After the introduction of shock wave lithotripsy (SWL), ureteroscopy (URS), and percutaneous nephrolithotomy (PCNL), the subspecialty of endourology was born in the late 1970s. The purpose of this study was to report milestones in Canadian endourology, highlighting Canada's contributions to the field.

Methods: A review of the literature was performed from the late 1970s to the present. The literature review included bibliographic and digital resources. Additionally, records and recollections by various individuals were used, including some directly involved. Results: Endourology was born in Canada when SWL, URS, and PCNL emerged as minimally invasive treatment options for stones in the early to mid-1980s. According to our research, the first PCNL was performed at the University of Toronto in 1981. Dr. Joachim Burhenne, a Harvard-trained radiologist from Germany, first used extracorporeal SWL in Canada at the University of British Columbia (UBC) for the treatment of biliary stones. Treatment for urinary tract stones followed at UBC and Dalhousie University. The first worldwide use of the holmium laser for lithotripsy of urinary tract calculi took place at the University of Western Ontario. Other endourology milestones in Canada include the formation of the Canadian Endourology Group and the emergence of the Endourological Society-accredited fellowship programs at the University of Toronto and Western University in the 1990s. Canada hosted the $21^{\text {st }}$ and $35^{\text {th }}$ World Congress of Endourology and Shock Wave Lithotripsy annual meeting in Montreal and Vancouver, 
respectively.

Conclusions: Canadian urologists have led many advances in SWL, URS, and PCNL over the past four decades, and for a relatively small community have made significant contributions to the field. Through the training of the next generation of endourologists at Canadian institutions, the future of endourology in Canada is bright.

\section{Introduction}

In 2015 Dr. Stephen Nakada's group published an article titled "The modern history and evolution of percutaneous nephrolithotomy" in the Journal of Endourology. ${ }^{1}$ This article was the inspiration for our research on the history of endourology in Canada. Dr. Arthur Smith et al coined the term endo-urology to refer to the "closed, controlled, diagnostic and therapeutic manipulations within the urinary tract, using sophisticated urologic instruments" in $1979 .^{2}$ Considering minimally invasive surgical procedures such as shock wave lithotripsy (SWL), ureteroscopy (URS) and percutaneous nephrolithotomy (PCNL) emerged on the global surgical scene in the 1970's, it follows that the entire history of endourology in Canada is found within the past 50 years. Despite this relatively brief history, there is no shortage of endourological innovations and advances that were developed in Canada. The main objective of this study was to report milestones in Canadian endourology, highlighting key contributions to the field of endourology that occurred in Canada.

\section{Methods}

A review of the literature was performed from the late 1970's - the birth of endourology as a subspecialty - to the present. The literature review included bibliographic and digital resources. Additionally, records and recollections by various individuals, including some directly involved, were used in our quest for information on the history of endourology in Canada.

\section{Results}

Endourology was born in Canada a few years after its inception in the U.S., Europe and other parts of the world. In the early to mid-1980's SWL, URS and PCNL surfaced as minimally invasive treatment options for urinary tract calculi in Canada. ${ }^{3-5}$ Figure 1 shows key milestones and highlights in Canadian endourology. 


\section{Shock wave lithotripsy}

Dr. H. Joachim Burhenne, shown in Figure 2, was a Harvard-trained radiologist from Germany and first physician to use extracorporeal SWL in Canada at the University of British Columbia (UBC) in the mid-1980's. ${ }^{6}$ By comparison, Prof. Dr. Christian Chaussy and his clinical research team pioneered SWL and on February 7, 1980 Chaussy performed the world's first SWL procedure on a patient at the University of Munich. ${ }^{7}$ Burhenne used SWL for the treatment of biliary stones and, by 1986, UBC and Dalhousie University were using it for the management of biliary and urinary tract stones. Victoria General Hospital in Halifax housed Eastern Canada's first SWL machine, a Dornier HM3 (Figure 3). By 1987, Toronto had opened the E.C. Bovey Lithotripsy Unit that was outfitted with its first SWL machine, a Siemens Lithostar (Figure 4). By 1989, Dr. Richard Norman's group had published their findings on post-SWL retroperitoneal air in 6 of 1,344 patients who had epidural anesthesia. ${ }^{3}$ In 2001, The University of Toronto endourology team were the first to publish a randomized controlled trial of mechanical percussion, inversion therapy and diuresis for residual lower pole stones following SWL. ${ }^{8}$ Dr. John Honey and the University of Toronto Lithotripsy Associates pioneered the protocol of SWL at a slower rate, initially trying out this technique in 2000, with artificial stones in a kidney stone model. ${ }^{9}$ In 2005 they published their first clinical, randomized controlled trial, comparing a rate of 60 with 120 shocks per minute. ${ }^{10}$ They showed significantly improved outcomes with the slower shock wave frequency, which resulted in a world wide adoption of this strategy. Despite its early promise and relatively widespread use in the U.S. due to mobile lithotripter units, SWL in Canada was limited to fixed units in major hospitals, and to date has remained centralized to a small number of institutions in Canada.

\section{Ureteroscopy}

To the best of our knowledge, ureteroscopy was first performed in Canada at the Health Sciences Centre Winnipeg in 1984 by Dr. Denis Hosking, and the first Canadian publication on rigid ureteroscopy soon followed by Hosking and Ramsey from the University of Manitoba in 1986. ${ }^{4}$ Although Dr. Hugh Hampton Young performed the world's first ureteroscopy in 1912 using a 12 French rigid pediatric cystoscopeunintentionally advancing the endoscope into a massively dilated right ureter in a child with posterior urethral valves ${ }^{11}$ - the world's first deliberate ureteroscopy using an actual ureteroscope was reported by Dr. Perez-Castro in $1980 .{ }^{12}$ Hosking later pioneered ureteroscopy in an ambulatory clinic setting under intravenous sedation in the 1990's and published his results in $1996 .{ }^{13}$ Perhaps one of Canada's most important contributions to endourology was the introduction of the holmium:yytrium aluminum garnet (YAG) laser for the fragmentation of urinary tract stones. Dr. John Denstedt from Western University (then known as the University of Western Ontario) performed the world's first 
ureteroscopic laser lithotripsy operation at St. Joseph’s Hospital in London in 1993 and reported Western's preliminary experience in 1995, a paper that also represented the first Canadian publication on flexible ureteroscopy. ${ }^{14}$ The initial Versapulse holmium:YAG laser unit (formerly Coherent Medical Group, Palo Alto, CA) used in London is shown in Figure 5. A multi-institutional Canadian collaboration between Western University and the University of Toronto led to the first published randomized controlled trial comparing non-stented versus stented ureteroscopic lithotripsy in 2001. This landmark paper showed that ureteral stents are unnecessary following uncomplicated ureteroscopy. ${ }^{15}$ Later, in 2005, the St. Michael's Hospital group published their experience with "hand-assisted" URS, and were the first to show that lower abdominal pressure aids passage of the semirigid ureteroscope into the proximal ureter. ${ }^{16}$ Today, both semirigid and flexible ureteroscopy have gained widespread popularity and are widely performed by most Canadian urologists.

\section{Percutaneous nephrolithotomy}

According to our research, Dr. John Honey from the University of Toronto performed the first PCNL in Canada at Toronto Western Hospital (TWH) in the 1981. He did so after his training with Dr. John Wickham in the U.K., where he assisted Wickham in performing a PCNL in 1980, one week after a radiologist obtained percutaneous renal access. At the time at TWH, no radiologist was performing percutaneous nephrostomies, so Honey obtained his own access based on what he had learned in the U.K., as shown in Figure 6. By comparison, Fernström and Johansson reported the world's first PCNL in 1976. ${ }^{17}$ Back in the early days of PCNL in North America, Dr. Ralph Clayman, one of the pioneers in endourology began offering courses on PCNL. Dr. Jack Sales from London, Ontario attended one of Dr. Clayman's early courses in Minnesota and then began performing PCNL at St. Joseph's Hospital in the Spring of 1984 with the assistance of several interested radiologists. Around that time, Drs. James Wilson and Hosking completed fellowships under Dr. Joseph Segura, who had radiologists perform the percutaneous renal access for PCNL. Soon thereafter, Hosking was interested in obtaining his own access, and became the first Canadian to establish retrograde nephrostomy as a safe and effective route for PCNL. He published his experience using two retrograde techniques - the Lawson and Hunter-Hawkins systems-in 1986. ${ }^{18}$ Clayman started championing urologists obtaining their own antegrade access for PCNL and a few years later Denstedt mastered the technique during his fellowship with Dr. Ralph Clayman. Honey's group was the first to perform semirigid percutaneous antegrade ureteroscopy in Canada at St. Michaels Hospital in the late 1980's (Figure 7), and were the first to report thorascopy-assisted PCNL that permitted high supracostal percutaneous renal access through the $9^{\text {th }}$ or $10^{\text {th }}$ intercostal space. ${ }^{19}$ Denstedt was the first to use the Swiss Lithoclast for intracorporeal lithotripsy in North America, and 
reported his initials results for renal, ureteral and bladder stones in $1992 .^{20}$ The proneflexed position for PCNL was introduced by the University of Toronto group, and was shown to improve access to the upper pole and provide more nephroscope mobility during lower pole mobility. ${ }^{21}$ Canadian endourologists from McGill University and Queen's University teamed up to resurrect outpatient PCNL ${ }^{22,23}$ more than 30 years after Preminger et al's initial report in $1986 .{ }^{24}$ After initially performing PCNL on a completely outpatient basis in 2007, they reported their combined results in 2015 that demonstrated the safety and feasibility of ambulatory PCNL in select patients. ${ }^{25}$ Since that time there has been a slow trend toward ambulatory PCNL in several countries. Although many community and academic urologists receive training in percutaneous renal surgery during their residency, today most urologists routinely performing PCNL are community or academic urologists with experience in percutaneous techniques and/or fellowships in endourology.

\section{Canadian Endourology Group}

Another endourology milestone in Canada was the formation of the Canadian Endourology Group (CEG), which occurred around the turn of the millennium. Drs. Denstedt, Honey and Denise Arsenault founded the CEG. Whereas the Endourological Society is the organization for endourologists globally, the Canadian Endourology Group is the national organization for urologists and endourologists interested in endourologyrelated educational and research collaborations. The CEG holds its annual general meeting in June each year in association with the Canadian Urological Association annual conference. Additionally, the CEG hosts multiple videoconference rounds each year on various endourology-related topics. These rounds are broadcasted across Canada to interested urologists and residents at both academic institutions and community hospitals. Several national research collaborations have been borne out of the CEG.

\section{World Congress of Endourology \& Shock Wave Lithotripsy}

Canada has hosted the World Congress of Endourology \& Shock Wave Lithotripsy on two occasions. In 2003, Denstedt served as President of WCE 2003, hosting the $21^{\text {st }}$ World Congress on Endourology and Shock Wave Lithotripsy annual meeting in Montréal. More recently, Drs. Ben Chew and Kenneth Pace served as Co-Presidents of WCE 2017 and hosted the 35 ${ }^{\text {th }}$ World Congress of Endourology and Shock Wave Lithotripsy annual meeting in Vancouver. Both meetings were well attended and well received by urologists, endourologists, industry and partners from around the world.

\section{Endourological society-accredited fellowships}

Another endourology milestone in Canada was the accreditation of endourology fellowships at the University of Toronto and Western University by the Endourological Society in the 1990's. ${ }^{26}$ Western's fellowship was the first accredited endourology 
fellowship outside the U.S., and Dr. Hassan Razvi the first graduate. ${ }^{27}$ Over the past 25 years, these two programs have graduated more than 50 endourology fellows who currently work across Canada and in at least 8 other countries.

\section{Conclusion}

Over the past 4 decades since endourology emerged in Canada in the 1980's, there have been several milestones in Canadian endourology. Canadian urologists have contributed significantly to advances in the field of endourology, and continue to do so. Through the training of the next generation of endourologists at Canadian institutions, the future of endourology in Canada is bright. 


\section{References}

1. Patel SR, Nakada SY. The modern history and evolution of percutaneous nephrolithotomy. J Endourol 2015;29:153-7.

2. Smith AD, Lange PH, Fraley EE. Applications of percutaneous nephrostomy. New challenges and opportunities in endo-urology. J Urol 1979;121:382.

3. Palmer BW, Norman RW. Retroperitoneal air, extracorporeal shock wave lithotripsy and epidural anesthesia. J Urol 1989;141:844-5.

4. Hosking DH, Ramsey EW. Rigid transurethral ureteroscopy. Br J Urol 1986;58:621-4.

5. Graham RT, Herschorn S. CT demonstration of irrigant extravasation following percutaneous nephrolithotomy. Can Assoc Radiol J 1988;39:284-5.

6. Becker CD, Fache JS, Gibney RG, Scudamore CH, Burhenne HJ. Choledocholithiasis: treatment with extracorporeal shock wave lithotripsy. Radiol 1987;165:407-8.

7. Chaussy C, Brendel W, Schmiedt E. Extracorporeally induced destruction of kidney stones by shock waves. Lancet 1980;2:1265-8.

8. Pace KT, Tariq N, Dyer SJ, Weir MJ, D'A Honey RJ. Mechanical percussion, inversion and diuresis for residual lower pole fragments after shock wave lithotripsy: a prospective, single blind, randomized controlled trial. J Urol 2001;166:2065-71.

9. Weir MJ, Tariq N, Honey RJ. Shockwave frequency affects fragmentation in a kidney stone model. J Endourol 2000;14:547-50.

10. Pace KT, Ghiculete D, Harju M, Honey RJ; University of Toronto Lithotripsy Associates. Shock wave lithotripsy at 60 or 120 shocks per minute: a randomized, double-blind trial. J Urol 2005;174:595-9.

11. Meldrum KK, Mathews R, Gearhart JP. Hugh Hampton Young: a pioneer in pediatric urology. J Urol 2001;166:1415-7.

12. Pérez-Castro Ellendt E, Martínez-Piñeiro JA. [Transurethral ureteroscopy. A current urological procedure]. Arch Esp Urol 1980;33:445-60. Spanish.

13. Hosking DH, Bard RJ. Ureteroscopy with intravenous sedation for treatment of distal ureteral calculi: a safe and effective alternative to shock wave lithotripsy. J Urol 1996;156:899-901.

14. Denstedt JD, Razvi HA, Sales JL, Eberwein PM. Preliminary experience with holmium: YAG laser lithotripsy. J Endourol 1995;9:255-8.

15. Denstedt JD, Wollin TA, Sofer M, Nott L, Weir M, D'A Honey RJ. A prospective randomized controlled trial comparing nonstented versus stented ureteroscopic lithotripsy. J Urol 2001;165:1419-22.

16. Dagnone AJ, Blew BD, Pace KT, Honey RJ. Semirigid ureteroscopy of the proximal ureter can be aided by external lower-abdominal pressure. J Endourol 2005;19:342-7.

17. Fernström I, Johansson B. Percutaneous pyelolithotomy. A new extraction technique. Scand J Urol Nephrol 1976;10:257-9.

18. Hosking DH. Retrograde nephrostomy: experience with 2 techniques. J Urol 
1986;135:1146-9.

19. Finelli A, Honey RJ. Thoracoscopy-assisted high intercostal percutaneous renal access. J Endourol 2001;15:581-4.

20. Denstedt JD, Eberwein PM, Singh RR. The Swiss Lithoclast: a new device for intracorporeal lithotripsy. J Urol 1992;148:1088-90.

21. Ray AA, Chung DG, Honey RJ. Percutaneous nephrolithotomy in the prone and prone-flexed positions: anatomic considerations. J Endourol 2009;23:1607-14.

22. Shahrour W, Andonian S. Ambulatory percutaneous nephrolithotomy: initial series. Urology 2010;76:1288-92.

23. Beiko D, Lee L. Outpatient tubeless percutaneous nephrolithotomy: the initial case series. Can Urol Assoc J 2010;4:E86-90.

24. Preminger GM, Clayman RV, Curry T, Redman HC, Peters PC. Outpatient percutaneous nephrostolithotomy. J Urol 1986;136:355-7.

25. Beiko D, Elkoushy MA, Kokorovic A, et al. Ambulatory Percutaneous Nephrolithotomy: What Is the Rate of Readmission? J Endourol 2015;29:410-4.

26. [No authors listed] Recognized Fellowship Programs in Endourology. J Endourol 2004;18:799-802.

27. [No authors listed] Recognized fellowship programs in endourology. J Endourol 1996;10:307-8. 


\section{Figures and Tables}

Fig. 1. Canadian endourological milestones and highlights.

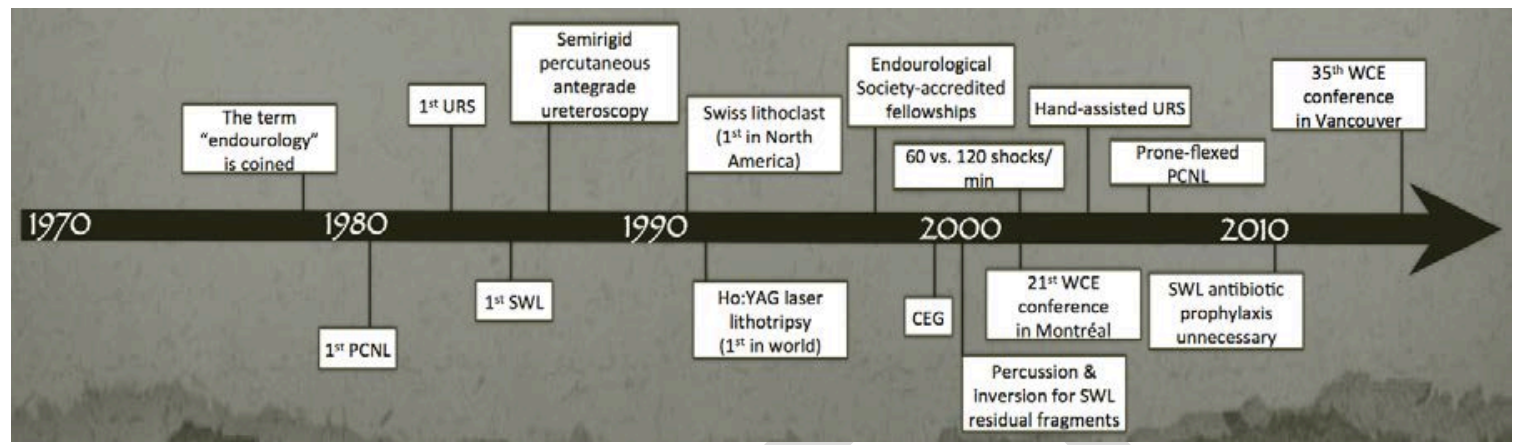

Fig. 2. Dr. H. Joachim Burhenne, first physician to use shock wave lithotripsy clinically in Canada.

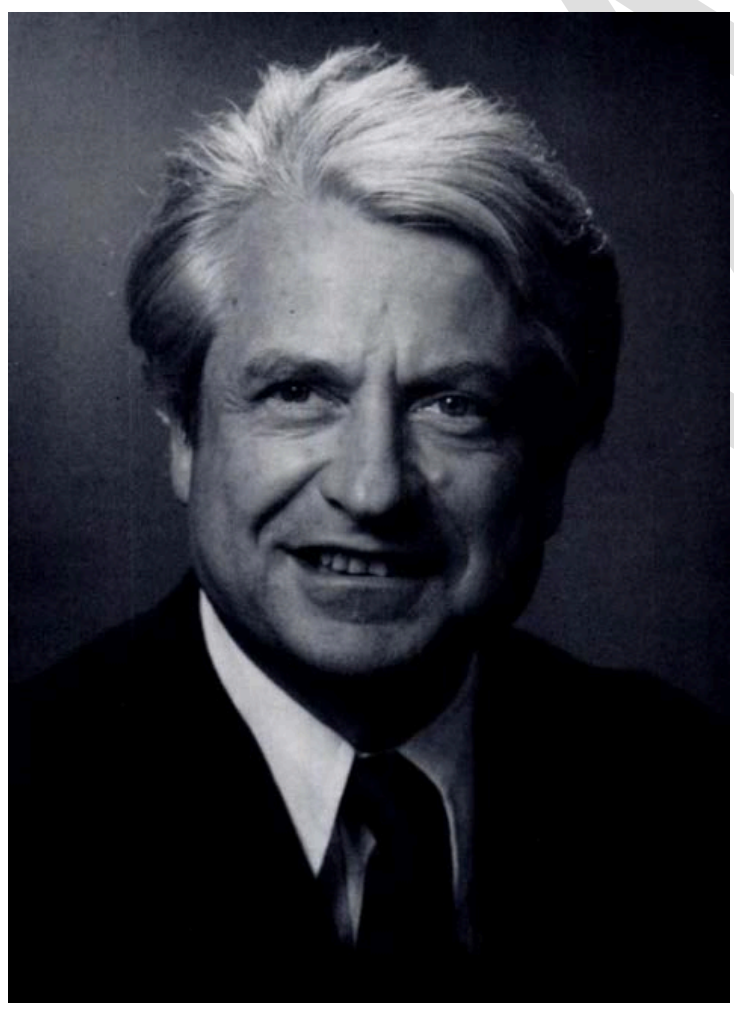


Fig. 3. Photograph taken in 1986 in the basement of Victoria General Hospital shows Dalhousie University’s first shock wave lithotripsy machine, a Dornier HM3.

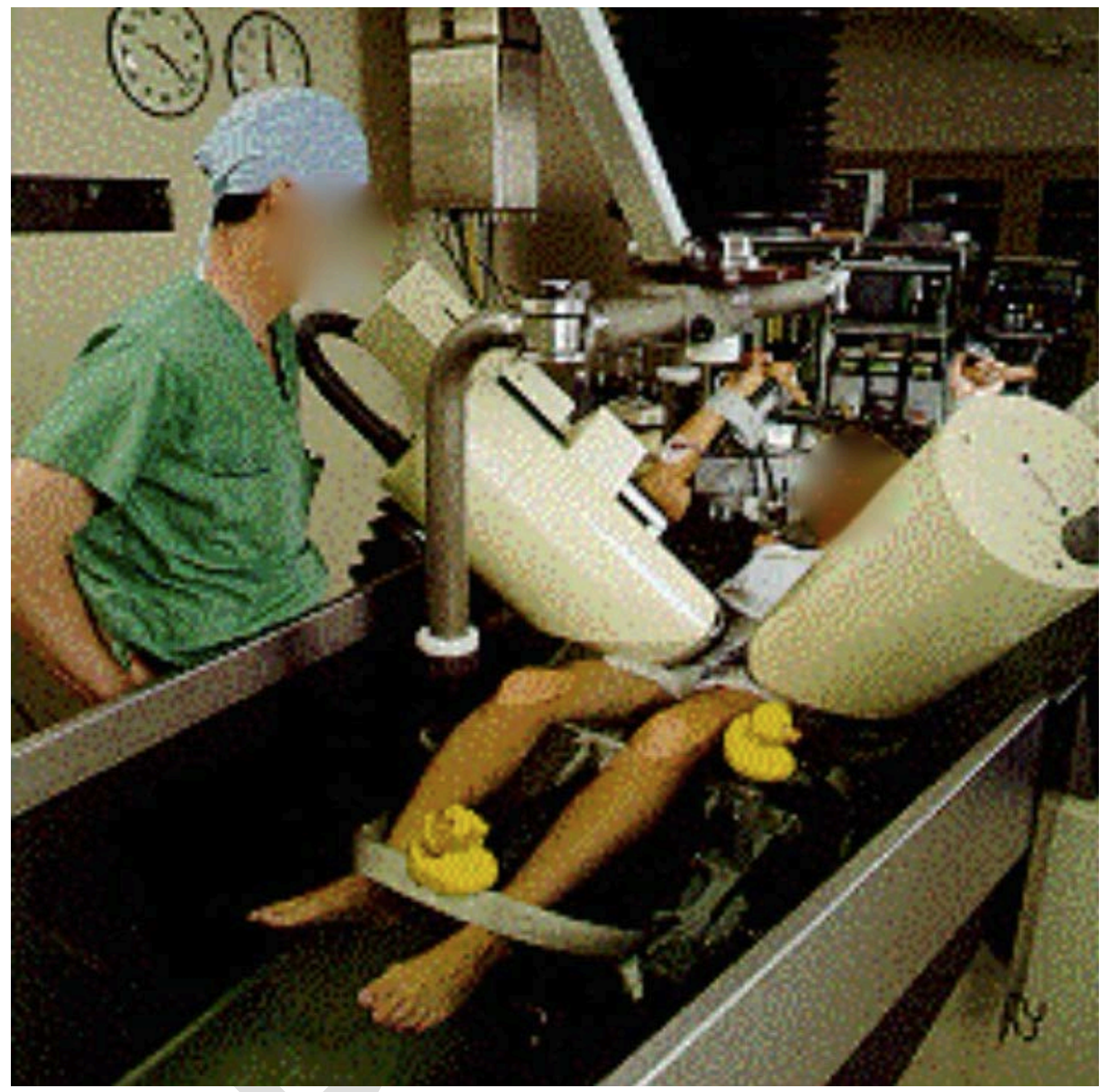


Fig. 4. Toronto's first shock wave lithotripsy machine, a Siemens Lithostar, in the E.C. Bovey Lithotripsy Unit.

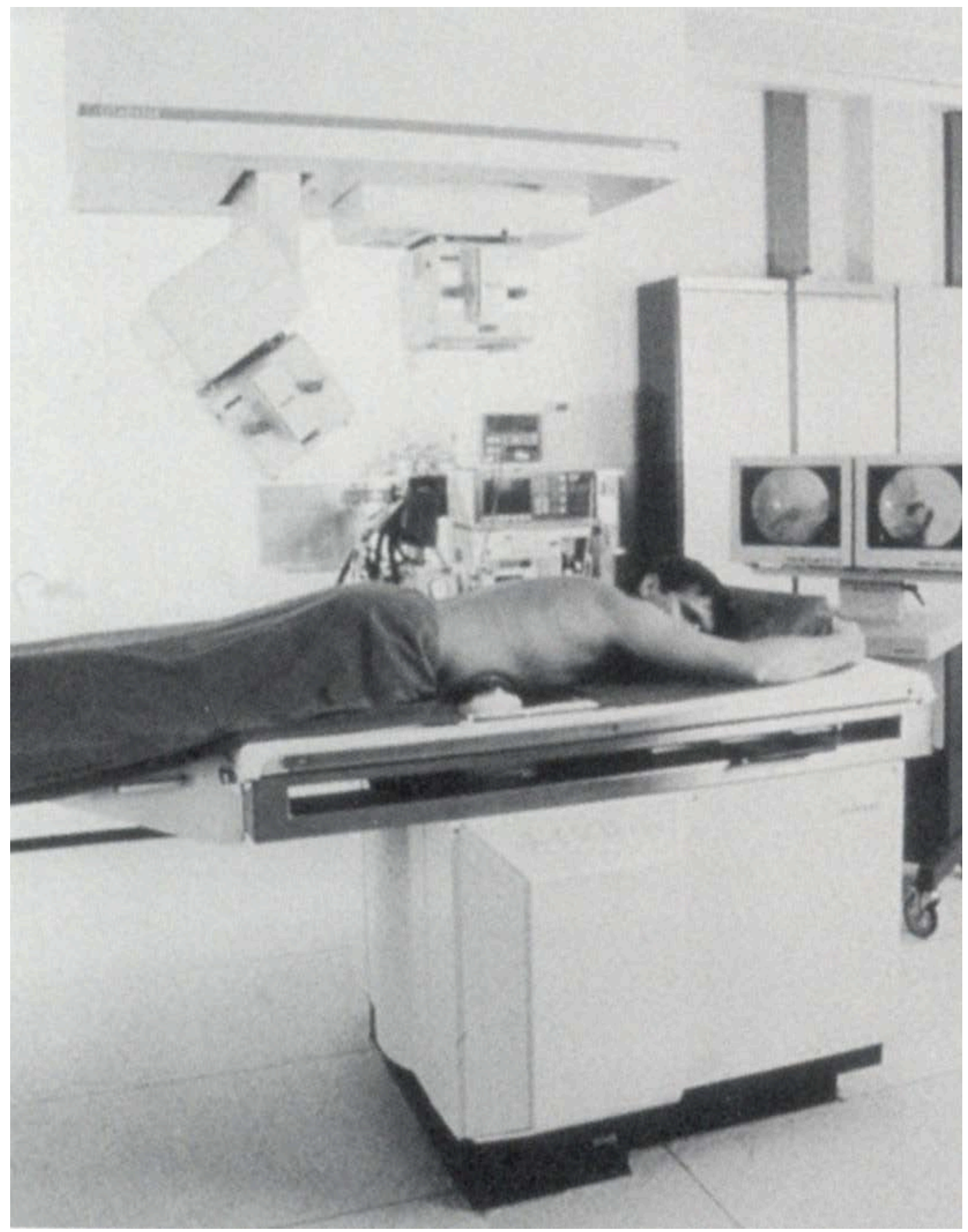


Fig. 5. Coherent's original Versapulse holmium:YAG laser unit, the world's first holmium laser used for ureteroscopic laser lithotripsy in London, Ontario by Dr. John Denstedt.
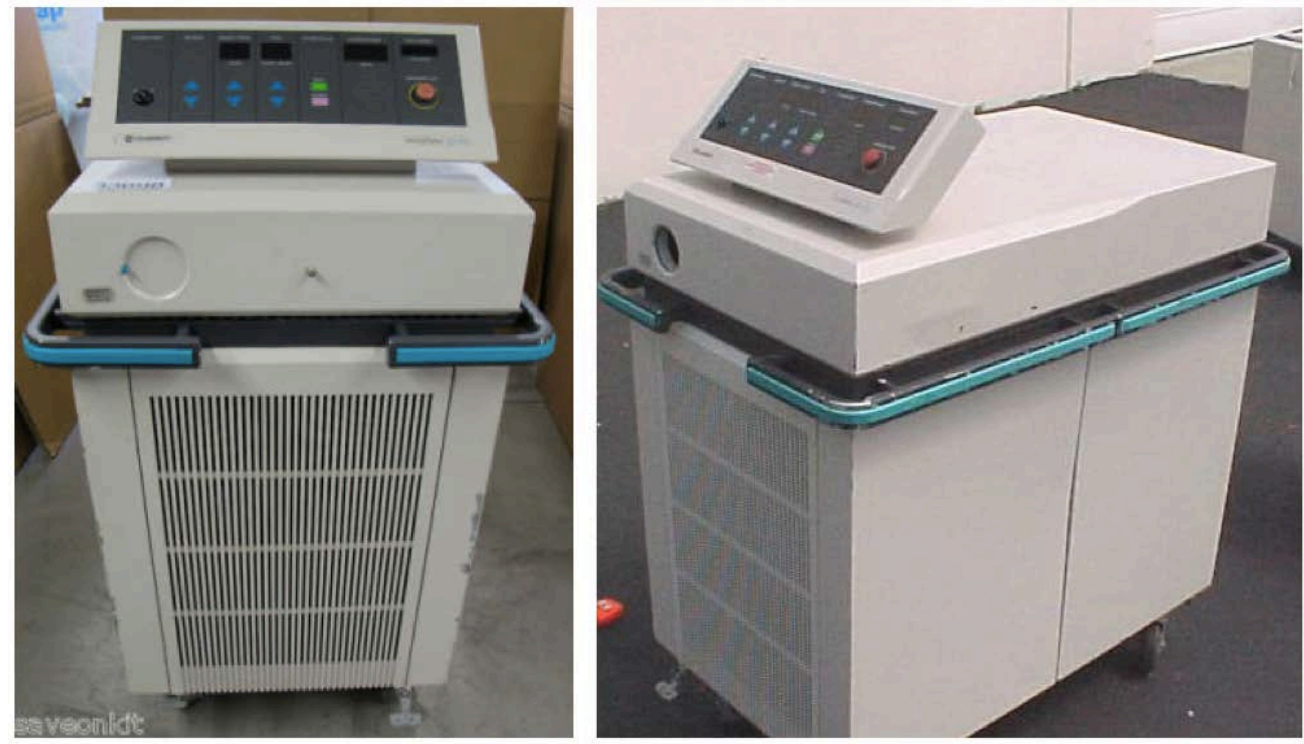

Fig. 6. Dr. John Honey performing tract dilation during percutaneous nephrolithotomy in 1981.

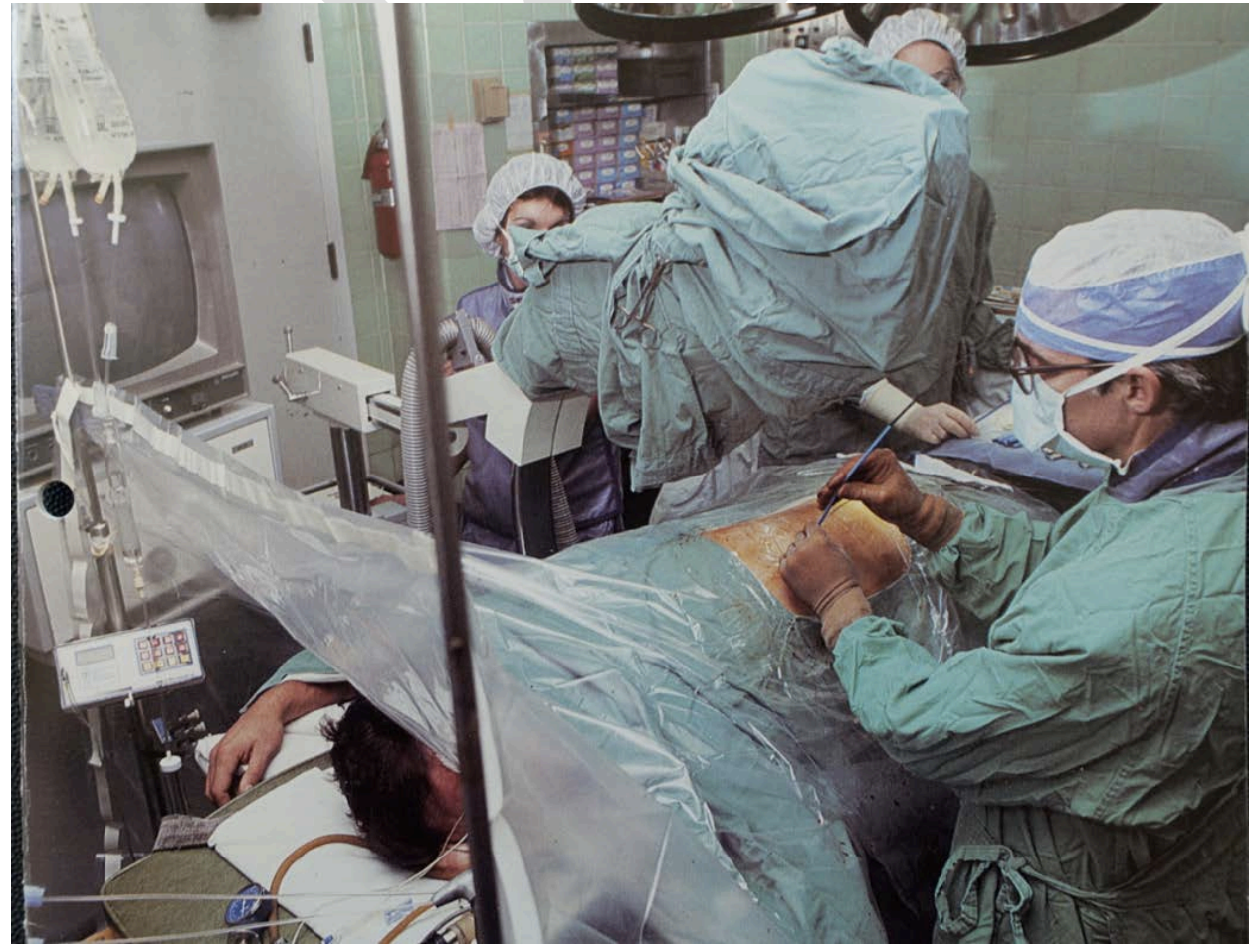


Fig.7. Semirigid percutaneous antegrade ureteroscopy by Dr. John Honey in the late 1980s.

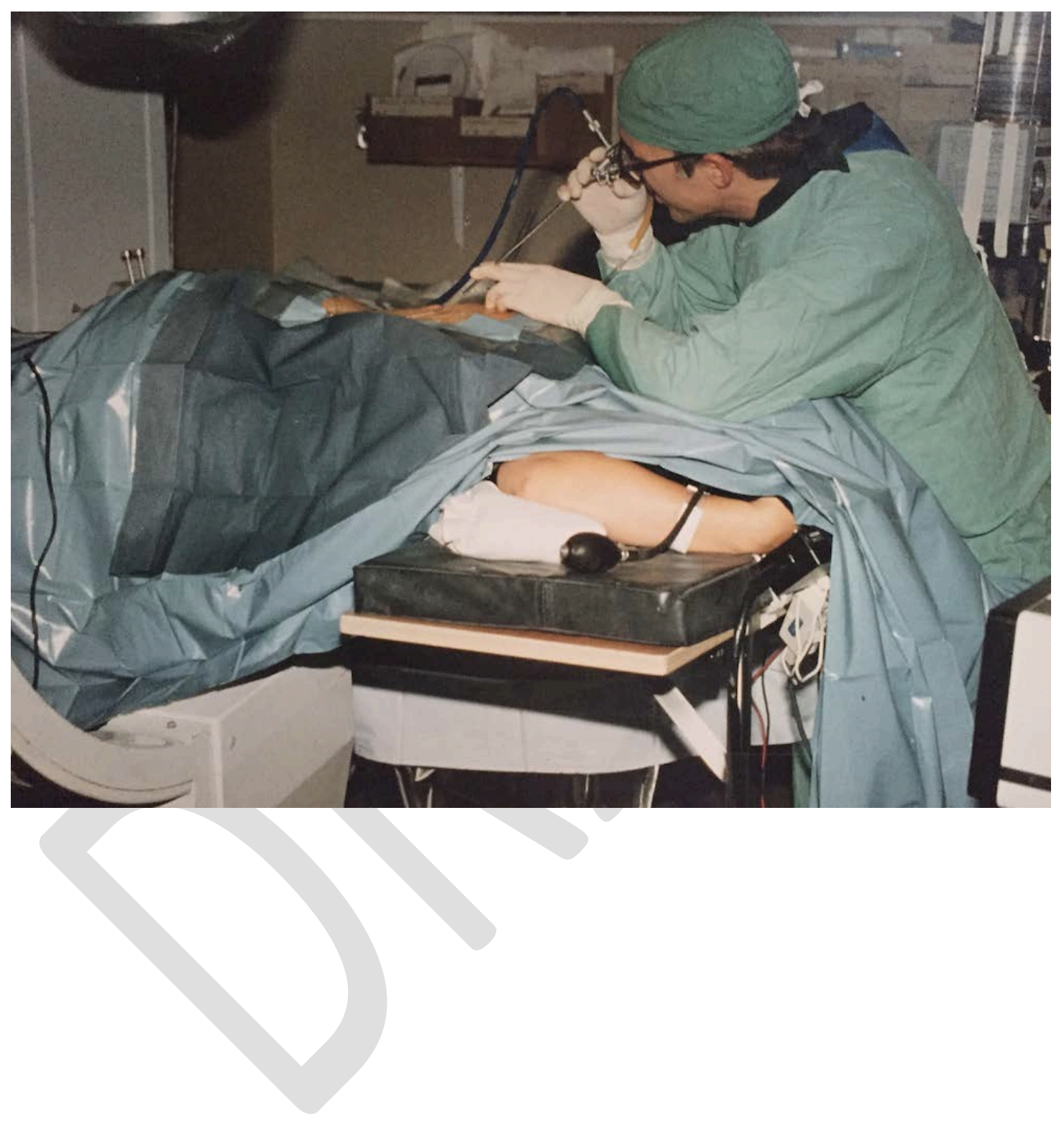

